\section{CORPUS PUBLISHERS}

\section{Corpus Journal of Dairy and} Veterinary Science (CJDVS)

\section{Volume 2 Issue 2, 2021}

Article Information

Received date : September 20, 2021

Published date: September 28, 2021

*Corresponding author

Camillo La Mesa, Dipartimento di

Chimica, Stanislao Cannizzaro,

Università di Roma La Sapienza, P. Aldo

Moro, 5-00185 Roma, Italy

\section{Keywords}

Cheeses and their Making; Food

Colloids; Weak Interactions

DOI: 10.54026/CJDVS1026

Distributed under Creative Commons CC-BY 4.0

\section{From Millk to Cheese: General Features of Four Typical Dairy Products from the Mediterranean Area}

\author{
Gianfranco Risuleo and Camillo La Mesa ${ }^{\star}$ \\ Dipartimento di Chimica, Stanislao Cannizzaro, Università di Roma La Sapienza, Italy
}

\section{Abstract}

The stability and maintenance of food plays a fundamental role in the preservation of its nutritional and organoleptic properties: therefore, since the dawn of civilization, mankind developed different forms of food conservation. The simplest one was possibly represented by simple cooking/roasting on different heat sources, but later relatively more sophisticated forms were developed: so drying, salting, and freezing have become part of the daily food preservation although this latter is nowadays practiced mainly on an industrial scale. Cheese possibly represents a very ancient of conserving fresh milk, via its transformation from a rapidly perishable commodity into a durable and palatable finished product. In this review, we give a condensed overview on the preparation of cheeses from the Mediterranean area that have reached a diffusion and appreciation throughout the world. Also, understanding the bio-molecular and chemico-physical processes underlying food preparation plays a pivotal role, therefore some insights in this particular aspect is also illustrated. Because of the conciseness of this contribution, we do not go into deeper details about the chemico-physical aspects of cheese making; however, extensive works on this subjects from our and other laboratories are found in the literature cited.

\section{Introduction}

\section{General considerations on food preparation and food colloids}

Mankind has invested a great effort in the optimization of food preparation and keeping. A number of procedures have been developed all over millennia of human history, possibly from the Neolithic Age up our days. Common food maintenance procedures are represented by smoking, cooking, drying, salting, and freezing even though this is a more recent achievement limited to an industrial scale [1-4]. Long-keeping products are represented by anchovy paste, smoked and dried stock fish, dried venison, and finally, cheese [5,6]: these foods constitute a very rich nutritional source of protein and fat, and last but not least give a decisive and crucial contribution to the palatability of the finished product. Transformation of fresh row milk into cheese represents a primordial way of keeping milk from deterioration: but it has become a widely appreciated gourmet food in practically all areas of the world. In any case, cheese is one of the most complex, and diversified foods as far as the extreme differences in organoleptic features of the final product. These derive essentially from the ripening agents (enzymes and microorganisms), animal origin of the fresh product (cow, sheep, goat), and the environmental conditions during maturation and aging. These factors contribute to the determination of the sensorial flavor of the final product which dominates the vast diversity of the cheese panoply. In any case it undisputable that cheese represents a widely diffused and appreciated commodity: it has been estimated that a great number of different cheese species are commercially available, with their number amounting to about 1800 different ones throughout world, although the authors are of the opinion that this figure is an under-estimation. Only in the USA, for instance, an astounding 6 million tons were produced in the time span 2013-2020 (https://www.cheese. $\mathrm{com} /$ ). Reviews on cheese and its making have appeared recently. In particular, a review article on some highly appreciated and commonly consumed cheese varieties consumed in the Mediterranean was very recently published [7]. Concerning food and nutraceutics, we have recently developed an increasing interest also in the nanotechnological aspects involved in the delivery of natural products in advanced biomedicine and the physico-chemical features underlying these processes [8-15]. It should be borne in mind that the food industry makes extensive use of stabilizers with different chemical, biochemical, and physicochemical features in addition to peculiar rheological properties. Adopting stabilizing agents is required by the shelf conservation time of industrially produced foods, which at times may be rather long. Essentially, stabilizers have the capability to adsorb onto surfaces [16]. Absorption is the result of a number of interacting combined forces including, steric, osmotic, and electrostatic effects, the reader is addressed to the classical works by Perutz [17] and the more recent one by Israelachvili [18]. The effects due different forces are rather cumbersome: in any case, the role of some forces in food stabilization and food bio-colloids is very extensively discussed and interpreted in the theory developed by Derjaguin-Landau-Verwey-Overbeek (DLVO) $[19,20]$; for details the reader is addressed to previously published work from us and other investigators [9-21 and 22].

From milk to cheese and yogurt: Two fundamental dairy products

The production of cheese and yogurt (and similar products, see below) derive from milk, be this row material crude, pasteurized, whole or partially degreased, and more recently also lactose free. However, significant differences occur between cheese- and yogurt-making procedures. Cheese undergoes a complex milk fermentation and which involves, in specific cases, a very long process of maturation and aging. This imparts to the finished product the unique organoleptic requirements in terms of appearance, flavor, taste, and texture. Yogurt is generated by the action of different bacterial organisms belonging to the genus Lactobacillus and Streptococcus: therefore, is produced by a simple bacterial fermentation of milk. Lactic acid acts on milk proteins and causes the change of the original milk texture and flavor generating yogurt and similar products like crème fraiche (mainly French), quark (mainly consumed in Germany), kefir (Europe Middle East), skyr and filmjölk (Iceland, Scandinavia). Cow's milk is the common row material to make yogurt, although goat milk variants are found mainly in the Eastern European countries like Greece and Turkey; the final product may be homogenized, strained (as in the case of Greek yogurt), or neither. Some very popular and up-to-date versions of nutraceutical probiotic yogurts forms, also defined as super-foods, are the final processing of milk mediated by bacterial strains like Bifidus actiregularis, protected by industrial patents: strictly speaking 
these milk products are not yogurt. Unlike yogurt, cheese ferments under the action of spores (yeast, molds) and bacteria. The handicraft and industrial scale production follow almost the same "protocol". The cheese-master feeds milk to a temperature-controlled vat where the growth of microorganisms metabolizing lactose is favored. Milk is usually pasteurized, but as required by new trends in human nutrition and marketing, crude whole milk is very often used: this leads to niche products with a higher added value.

Lactose is transformed into lactic acid. Microorganisms responsible for milk transformation into cheese may be fresh, frozen, or lyophilized in the form of paste, powder, or pellets. Some micro-organisms produce only lactic acid are, therefore, their cheese processing is defined as homo-fermentation. On the other hand, microorganisms producing carbon anhydride, alcohol, aldehydes, ketones, are known as heterofermentative. Both processes, homo- and hetero-fermentation, produce cheeses with typical features in terms of taste, macroscopic textures such among others, the presence and size of bubbles. When the cheese-master and his/her technicians judge that enough lactic acid has been developed, they add rennet which constituted by a complex mixture of enzymes obtained from the stomach of ruminants. Rennet precipitates casein it contains chymosin which converts casein to para-caseinate, the main component of cheese curd. Thereafter, milk is left to form curds and after their formation, milk fat is trapped into a casein matrix; at this point whey and water must be eliminated, causing a partial but significant dehydration of the mass: this was traditionally carried out through squeezing/pressing of the mass through the cheese cloth with an appropriate mesh. Cheeses are, prior to waxing or coating with animal melted fat, pre-ripened in brine: this treatment, depending on each cheese variety may last from a few days to two or three weeks. Vacuum packing removes oxygen and prevents fungal growth during maturation, but this procedure is mainly carried out in the industrial cheese trade. A series of maturation steps in controlled temperature and humidity chambers, permits the development of surface molds which favors cheese ripening and prevents deterioration by competing detrimental fungi: for details see [9-11]

\section{Four Representative Cheeses from the Mediterranean Area}

\section{Pecorino Romano}

Pecorino in obtained from sheep milk (pecora, hence pecorino, is the Italian word for sheep). It is an extremely diffused cheese in Italy. Practically, in center-southern Italy there is no area, regional territory, town, or small village that does not boast its own pecorino which may be found in the form of young soft cheese (caciotta) or mature hard cheese. Many of them are branded as PDO (Protected Designation of Origin). Possibly the roman pecorino (protected European Union laws) is the best known and appreciated in the world, although the definition romano has to be considered a misnomer since it is nowadays produced mainly in Sardinia in the area of Macomer. However, by legal act, romano is produced exclusively from the milk of sheep raised either in Lazio or, in Sardinia. In any case, Pecorino Romano must be made with lamb rennet from animal raised in the same areas of production. Pecorino Romano, also defined sometimes as the Black King, due to its coating of a thin layer of black wax (unfortunately substituted in our modern era by synthetic films) has been known literally for millennia. Latin author like Varro and Pliny the Elder described its production and consumption about 2,000 years ago $[23,24]$. Moreover, Pecorino Romano was a staple in the diet for the legionaries of ancient Rome as well as the sausages (luganica, originating from Lucania, a region in Southern Italy). These were foods of high nutritional value, easy to keep and which would not spoil during the endless Roman military campaigns (Figure 1). Curiously, a still surviving tradition in Rome is that on May first, Romans eat pecorino romano with fresh fava beans during daily family excursions in the green surroundings outside Rome.

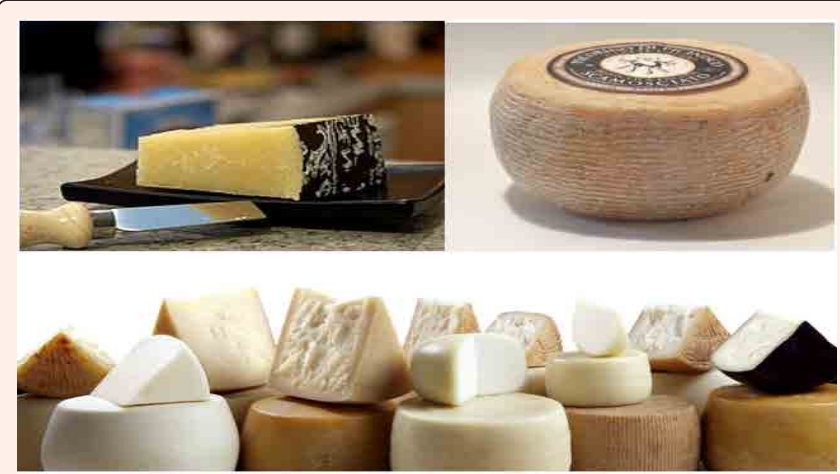

Figure 1: Left: A slab of Pecorino Romano with its typical black veneer.
However, the reader should be aware that, as stated above the number and variety of pecorino cheese existing in Italy are very numerous, just to mention but a few ones: Pecorino di Pienza (Tuscany, a territory which possibly contributes with the highest number of pecorino varieties); Pecorino stagionato in foglie di noce (Tuscany, matured in walnut leaves); Pecorino flavored with whole black pepper grains and saffron (from some areas of Sicily); Pecorino di Farindola (Abruzzo); Pecorino di Filiano (Basilicata); pecorino from Moliterno (Abruzzo, highly appreciated).

Pecorino Romano is one of the five cheese qualities most exported in the world. In the USA a "romano cheese" is available on the market, but it is made of cow milk and does not share with pecorino romano any of the original organoleptic features. Right: Pecorino from Moliterno, in the region of Abruzzi (center Italy) highly appreciated by cheese lovers. Bottom: The extreme variety of pecorino cheeses in texture, aging, softness. Unfortunately, the picture cannot convey to the reader the smell, flavor, and taste of the produce.

\section{Butirro Silano}

Butirro, sometimes also defined as burrino is typically produced in Calabria, the area comprehended in the heel of the Italian peninsular boot. It derives from the Caciocavallo, a semi-soft cheese diffused in the whole Mediterranean area. Caciocavallo owes its name to the fact two pear-shaped fresh cheeses are bound together by a straw and left to a age briefly astride a wooden pole (cacio a cavallo, i.e. horse-mounted cheese) See, for instance: https://artsandculture.google.com/exhibit/caciocavallo-silano/ gQefE0YT?hl=it. In Albania, just to make an example, but also in other territories of the Balkans, a cheese named kaçkavall exist: the assonance with the word caciocavallo is quite perceivable although the two cheeses have very little resemblance in texture and culinary usage. The Alabanian kaçkavall is usually consumed grilled as meze while gjizë, another popular cheese from the same Mediterranean area, resemble mostly the Italian ricotta (Figure 2). The Serbian Kačkavalj resembles morphologically and organoleptically the Italian caciocavallo; the Serbian version may be made also with sheep, the Italian one is only from cow milk. Butirro is eaten fresh, after a brief maturing time and is filled with butter: this was an ancient way to avoid butter to become rancid. It is a double structure cheese with a very thin crust and a with color paste ranging from almost pure white to pale yellow. The weight is seldom above 300 grams and it is produced almost exclusively on the Pollino mountain range in Calabria. There is a more modern version of the typical butirro, sold (alas!) in Tetrapack boxes filled with butter in which 2 to 3 centimeters-small "provole" (small semi-dried mozzarella cheeses) are drowned. The taste is unique and gluttonous, but a word of warning for the reader: the blood cholesterol title is bound to shoot up to alarming levels.

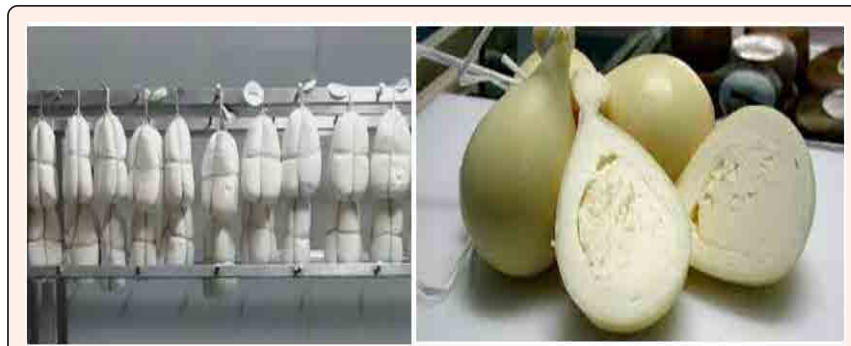

Figure 2: Left, Caciocavallo hanging in pairs across a pole to ripen.

Traditionally to pole was wooden, but this is what one has to pay to progress and industrial rationalization. Right, Butter filled Calabrian butirro.

Tulum

Tulum is a typical Turkish cheese. The row material for Tulum is goat's milk which has a considerably higher fat level as compared to milk from other animals, ruminants or not. The milk is heated to about $30{ }^{\circ} \mathrm{C}$, a starter culture is added and souring thus initiates: coagulation starts rapidly (in about an hour) where after the milk is converted into curds and whey. The curd is cut into small cubes and the whey is drained. At this stage the temperature is maintained constant. The curds are cooled, pressed through a cheese cloth, and hung for several hours for further draining and initial curing. The row curds are pressed into a wooden form under a weight for several hours allowing more elimination of whey. After this process the fresh non mature cheese mass is cut into pieces, about the size of 4 by 10 centimeters and immersed in brine where they are left for at least 24 hours, after which they are shelf dried and matured for at least one day.

Citation: : R Gianfranco, L M Camillo (2021) From Milk to Cheese: General Features of Four Typical Dairy Products from the Mediterranean Area. Corpus J Vet Dairy Sci 2: 1026 
The process ends with manual crushing and kneading of the curds, more raw goat milk is added and the whole mélange is stuffed into a goat hide. Salt is added on top of the filling, the container is closed with a rope and stored at cellar temperature to ripen. The container may be occasionally perforated to allow further leakage of whey and consequent drying. Unlike homemade tulum, the commercial product is made of partially de-greased goat's milk and kneaded with water buffalo or sheep milk. Ripening occurs essentially according to same "protocol", even though ripening is completed in plastic barrels. However, his results in a less durable product which may become moldy and does not have, according to experienced connoisseurs the same flavor and taste. Tulum cheese originating from different parts of the country may differ in taste due to variation in production techniques. Tulum cheese of Çimi for instance, is produced in the Antalya Province in Mediterranean Region, while other ones are produced in central Anatolia, on the Aegean coast and Black Sea areas (Figure 3). Allegedly, their taste and flavor may change quite significantly due differences production process.

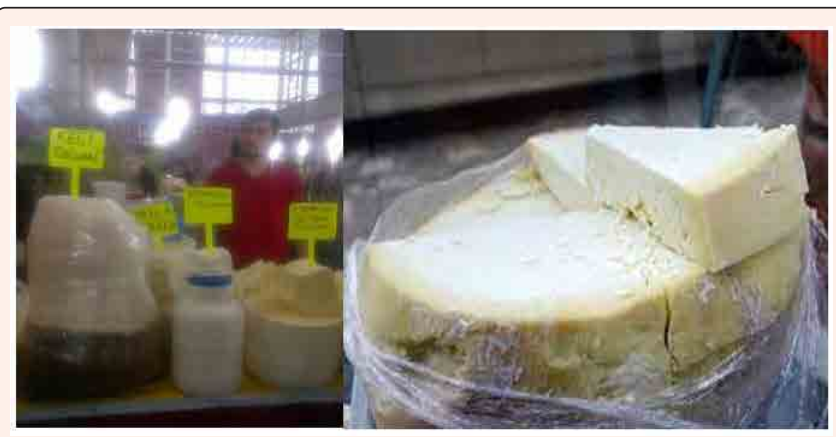

Figure 3: Left, Tulum cheese from Erzinca for sale on a local market. Right Tulum from Divle in the synthetic skin bag.

Pule
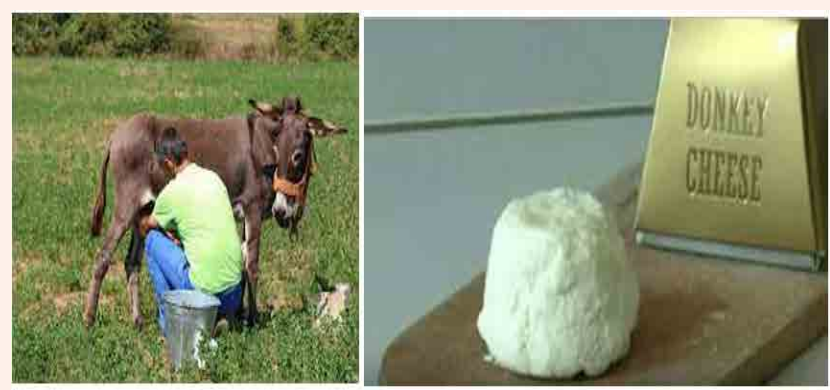

Figure 4: Left, A Jenny (she-donkey) during one of the three daily milking operations at the Zasavica reserve; Right, fresh Pule cheese, packaged and ready for the market.

Pule or magareći sir is produced in Serbia. This cheese may also be considered as a gastronomic curiosity. It is one of the most expensive cheeses, if not the most expensive one, made in the world; its market price per kilo may be as high as 1200 euros (over 1300 US dollars); but information exists about pule being marketed at four or five times this price. Just for a comparison, the reader should be aware that Scandinavian cheese from moose milk is priced at about 500 euros per kilogram, while the Italian Bitto Storico (a brand name) follows up at about 250. A second feature is that pule is made from the milk of Balkan she-donkeys (also known as jennys) of the homonymous breed. Furthermore, its production is limited to only one site in Serbia: a farm inside the Zasavica reserve, not far from Belgrade, where about 100 endangered Balkan donkeys find refuge. Donkey milk is exceptionally rare and its production is low: a jenny produces only a scant two liters of milk per day (one cow champion may arrive to 50 or more liters). These donkeys are milked manually three times a day and each action produces slightly less than a quarter of a liter of milk, in fact no milking machinery would be convenient in such a specialized business: but, it takes about 25 liters of donkey milk to produce just 1 kilogram of cheese and furthermore, donkey milk contains significantly fewer solids than cow milk. This means that more milk is needed to make the equivalent amount of hard cheese and donkey milk is marketed at about twenty to ninety euros the liter. During the pule making process, no particularly expensive ingredients are used: thus, the price of the finished treasure is due practically only to rarity of the row product and to human labor. Even though this farm-kept animals are feed with prime fodder, the frugality of donkeys is proverbial. Pule is a characteristic feature of Serbian cuisine, however it is extremely rare to find and hard to buy (Figure 4). Concerning the organoleptic feature of pule, the gourmets who had the privilege of trying it, define the flavor of mature cheese rather similar to, possibly stronger than the Spanish Queso Manchego: definitely more affordable for almost all pockets. Remarkable features of the donkey milk consist of its low-fat content, in the hypo-allergenic action and its biochemical composition which renders it very similar to human breast milk. The reader should check this Youtube clip for very interesting information about pule: https://www.youtube.com/watch?v=KZAp4r0n0B0-

\section{Conclusion}

The world of cheese is extremely variegated. Cheeses are made in all continents and countries: the Americas, Africa and Asia have all their own traditional cheeses. There are estimates that the number of this indeed palatable produce in the world amounts to at least a few thousands, for instance only in Italy eight hundred fifty different cheese have been counted. But the authors think that no reliable estimation can be really made in fact, there are home-made cheeses that do not go into the final number of this product. Also, the starting material, being milk in all cases, can be obtained by cow, sheep, goat, buffalo, yak, zebu, camel, donkey and so forth. But also, non-dairy cheeses exist, for instance those dedicated to vegan consumers. Therefore, it is almost impossible to cover in a short review article such as this one all possible aspects of cheese and its making: that would take many written volumes, tomes, about the subject. In this short work we focused on two very popular Italian cheeses, pecorino and butirro as well as two more exotic kinds like Tulum and the Serbian Pule. However, milk is the basic (almost sole) ingredient of the transformation to cheese: it is serendipitous how the process of cheese making changes the primary row material in such a diversified world of tastes and flavors. Some other transformations of row material into delicacies occur. Consider for instance the transformation of a pork leg into ham: Parma Ham is radically different from Spanish Jamon or from Prague Ham, not to speak about Pastrami; or the transformation of the inedible fresh olives into the delikatessen appreciated by most people all over the world. All in all, these treatments of row material were at the beginning of the human history, probably, a stratagem to avoid food decay and conserve its nutritional properties and palatability: the results of human ingenuity can produce at times really surprising results.

\section{References}

1. Matthews KR (2011) Review of published literature and unpublished research on factors influencing beef quality. EBLEX R\&D UK Agric. Horticulture Develop.

2. Richardson M, Matthews K, Lloyd C, Brian K (2012) Meat quality and shelf life. Better Returns Progr. EBLEX Agric. Horticulture Develop.

3. Dalby A (2013) Food in the ancient world from A to Z. Taylor \& Francis.

4. Martínez-Guido SI, Betzabe Gonzales-Campos J, El Halwagi MM, PonceOrtega JM (2017) Sustainable optimization of food networks in disenfranchised communities. ACS Sustainable Chemistry \& Engineering 5: 8895-8907.

5. Asher D (2015) The art of natural cheesemaking. Vermont: Chelsea Green Publishing, USA

6. Almena-Aliste M, Mietton B (2014) Cheese classification, characterization, and categorization: A global perspective. Microbiol Spectr 2: CM-0003-2012.

7. Bouroutzika E, Proikakis S, Anagnostopoulos AK, Katsafadou AI, Fthenakis GC, et al. (2021) Proteomics analysis in dairy products: Cheese, A review. Applied Sciences 11: 7622.

8. La Mesa C, Risuleo G (2018) Stabilization of food colloids: The role of electrostatic and steric forces. In: Milani J (Ed.), Some new aspects of colloidal systems in foods.

9. La Mesa C, Risuleo G (2020) Biophysical and molecular biochemistry of the dairy production chain: From milk to cheese. Corpus Journal of Dairy and Veterinary Science (CJDVS) 1: 1009.

10. La Mesa C, Corbo A, Gkouvi A, Risuleo G (2020) Bio-active principles from the animal and plant kingdom: A review. (2020) Advance Research in Organic and Inorganic Chemistry (AROIC) 1.

11. La Mesa C, Risuleo G (2020) Some remarks on colloid stability: Selected examples taken from the milk chain for food prepares. Colloids Interfaces 4: 58.

12. Risuleo G, La Mesa C (2021) Biological activities and potential nano-technological delivery of resveratrol. Nutraceuticals: Efficacy, Safety, and Toxicity. In: Gupta, Lall, Srivastava (Eds.) Second Edition. pp. 519-535. 
13. La Mesa C, Risuleo G (2021) On concept of hybrid. Colloids and Interfaces 5: 3353.

14. Mesa CL, Ranalison O, Randriantseheno LN, Risuleo G (2021) Natural products from madagascar, socio-cultural usage, and potential applications in advanced biomedicine: A concise review. Molecules 26: 4507.

15. Risuleo G, La Mesa C (2021) Natural products, nano-vectors, and advanced biomedicine: ancient remedies and innovative perspectives. Academia Letters.

16. Nambam JS, Philip J (2012) Competitive adsorption of polymer and surfactant at a liquid droplet interface and its effect on flocculation of emulsion. Journal of Colloid and Interface Science 366: 88-95.

17. Perutz MF (1978) Electrostatic effects in proteins. Science 201: 1187-1191.

18. Israelachvili JN (2015) Intermolecular and Surface Forces. ( $3^{\text {rd }}$ edn), Academic Press, US.
19. Derjaguin B, Landau L (1941) Theory of the stability of strongly charged lyophobic sols and of the adhesion of strongly charged particles in solutions of electrolyte. Acta Physicochimica U.R.S.S. 14: 633-640.

20. Grasso D, Subramaniam K, Butkus M, Strevett K, Bergendahl J (2011) A review of non-DLVO interactions in environmental colloidal systems. Reviews in Environmental Science and Biotechnology 1: 17-38.

21. Wennerstroem H (1982) The cell model for polyelectrolyte systems. Exact statistical mechanical relations, Monte Carlo simulations, and the Poisson-Boltzmann approximation. The Journal of Chemical Physics 76: 4665-4672.

22. Chen W (1992) Energy barriers for thermal reversal of interacting single domain particles. Journal of Applied Physics 71: 5579.

23. (2015) Pecorino Romano DOP.

24. Pecorino Romano: The Story Behind One of Italy's Oldest and Most Famous Formaggio, Italy. 